\title{
Markers of equine placental differentiation: insights from gene expression studies
}

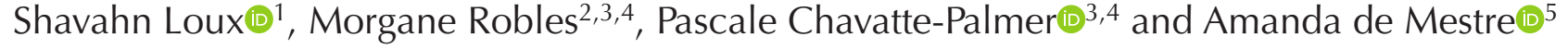 \\ ${ }^{1}$ Maxwell H. Gluck Equine Research Center, Department of Veterinary Science, University of Kentucky, Lexington, \\ Kentucky, USA, ${ }^{2}$ INRS Centre Armand-Frappier et Santé Biotechnologique, Laval, Québec, Canada, ${ }^{3}$ Université \\ Paris-Saclay, UVSQ, INRAE, BREED, Jouy-en-Josas, France, ${ }^{4}$ Ecole Nationale Vétérinaire d'Alfort, BREED, \\ Maisons-Alfort, France and ${ }^{5}$ Comparative Biomedical Sciences, Royal Veterinary College, Hatfield, UK
}

Correspondence should be addressed to S Loux or A de Mestre; Email: shavahn.loux@uky.edu or ademestre@rvc.ac.uk

\begin{abstract}
Development and the subsequent function of the fetal membranes of the equine placenta require both complex and precise regulation of gene expression. Advancements in recent years in bioinformatic techniques have allowed more extensive analyses into gene expression than ever before. This review starts by combining publically available transcriptomic data sets obtained from a range of embryonic, placental and maternal tissues, with previous knowledge of equine placental development and physiology, to gain insights into key gene families relevant to placentation in the horse. Covering the whole of pregnancy, the review covers trophectoderm, yolk sac, chorionic girdle cells, allantoamnion and allantochorion. In particular, 182 predicted 'early high impact' genes were identified (>100 transcripts per million (TPM) and >100 fold-change) that distinguish between progenitor trophectoderm, chorionic girdle tissue and allantochorion. Furthermore, 71 genes were identified as enriched in placental tissues (placental TPM > 10, with minimal expression in 12 non-placental TPM $<1$ ), including excellent candidates for functional studies such as IGF1, apolipoproteins, VGLL1, GCM1, CDX2 and FABP4. It is pertinent that future studies should focus on single-cell transcriptomic approaches in order to determine how these changes in gene expression relate to tissue composition and start to better define trophoblast subpopulations in the equine placenta. Future functional characterisation of these genes and pathways will also be key not only to understanding normal placental development and fetal health but also their potential role in pathologies of pregnancy. Reproduction (2022) 163 R39-R54
\end{abstract}

\section{Introduction}

Equine pregnancy is characterised, among other physiological aspects, by a long gestation (11 months), a late implantation ( $>35$ days) and four distinct placental tissue types. Two short-lived tissues, yolk sac and endometrial cups derived from an invasive chorionic girdle, support the pregnancy for the first 50 and 100 days respectively. The definitive, diffuse epitheliochorial allantochorial placenta in the mare is however the primary tissue that supports a single offspring throughout gestation assisted by the fourth tissue type, the allantoamnion that immediately surrounds the fetus. Placental formation is both complex and unique but, in common with other mammalian species, requires contributions from three cell lineages, ectoderm, endoderm and mesoderm, as described in Fig. 1.

Until 10 years ago, studies of the key molecules involved in regulating equine placental development were limited to targeted candidate-gene PCR and immunohistochemical descriptions of the bilaminar and trilaminar yolk sac, the chorionic girdle and chorioallantois between 2 months and term. Since the sequencing of the equine genome (Wade et al. 2009), we have observed a rapid expansion in the availability of molecular tools and bioinformatic resources that could be now applied to equine studies, allowing an improved understanding of equine placental gene expression and associated regulatory pathways. Similar to other species, 3-dimensional structure, ligand availability, transcription factor and epigenetic modifications are all examples of factors demonstrated to regulate placental gene and/or protein expression in the mare. Identification of these factors that regulate early placental growth, along with their downstream mediators, is crucial not only for our knowledge of what is required for development of a healthy offspring but to also shed light on underlying causes of pregnancy failure and mechanisms of gestational programming of the offspring (Robles et al. 2022).

Studies using microarrays and next generation sequencing (NGS) to investigate gene expression in equine placental tissue extend from descriptions of the primary derivative membrane, the blastocyst-derived 


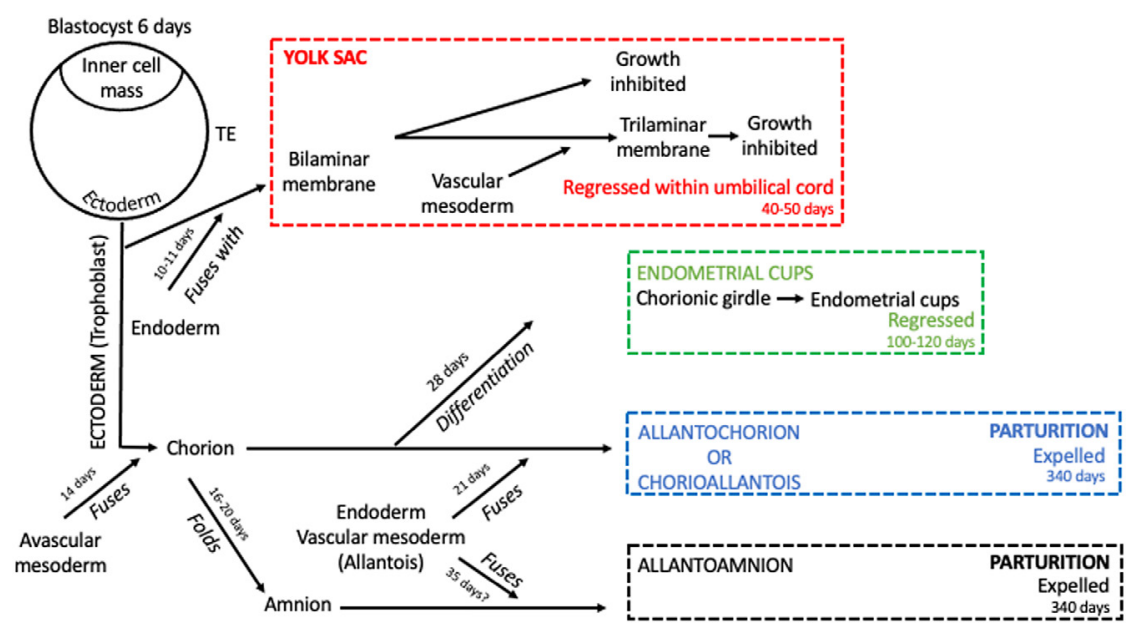

Figure 1 Schematic illustrating the four main placental membranes in the mare, their lifespan and how the three cell lineages, ectoderm, endoderm and mesoderm, each contribute to the membranes starting from a day 6 early blastocyst comprised of an inner cell mass (ICM) and trophectoderm (TE). The bilaminar membrane of the yolk sac forms from fusion of the ectoderm and endoderm which is later lined by vascular mesoderm to give rise to the trilaminar yolk sac wall. The chorion forms when the TE is lined by avascular mesoderm around day 14 of pregnancy. The chorion then contributes to the three other placental tissues: the endometrial cups, the allantochorion and allantoamnion. The chorionic girdle trophoblast is derived from a specialised region of the chorion abutting the newly developing allantochorion. The allantochorion forms when the chorion fuses with the allantois composed of endoderm and vascular mesoderm. The chorion folds around the embryo proper to give rise to the amnion which is similarly lined by allantois. trophectoderm (TE; Iqbal et al. 2014), to chorionic girdle (Brosnahan et al. 2012, Read et al. 2018a) and term chorioallantois (Robles et al. 2018, Loux et al. 2019a). The majority of these studies have focused on characterising tissues of mixed cellular composition emphasising the importance of interpreting these observations alongside our understanding of tissue composition (Fig. 1) and cell types present (Fig. 2) in the four main placental tissues in equids.

This review performed a meta-analysis using publically available published transcriptomes to enable us to compare gene expression across multiple placental tissues derived from blastocysts through to term pregnancies with as little bias as possible. We then reviewed this data alongside the published literature and our knowledge of tissue composition to define how expression changes over time within the distinct extra- embryonic membranes. We then went on to identify genes highly enriched in placental tissue as well as define genes that differentiate the two main lineages of early equine placental tissue, the chorionic girdle and allantochorion.

\section{Materials and methods}

In order to compare data for this review from multiple studies whilst minimising bias, raw data were pulled from the Sequence Read Archive (https://www.ncbi.nlm.nih.gov/ sra), with individual files identified by first searching for Equus caballus using RNA as a filter (1550 samples on 11/1/2019). All reproductive tissues derived from healthy individuals were selected, then screened for duplication and quality. When duplicate studies with equivalent tissue types were present (e.g. diestrus endometrium), the study with higher read quality

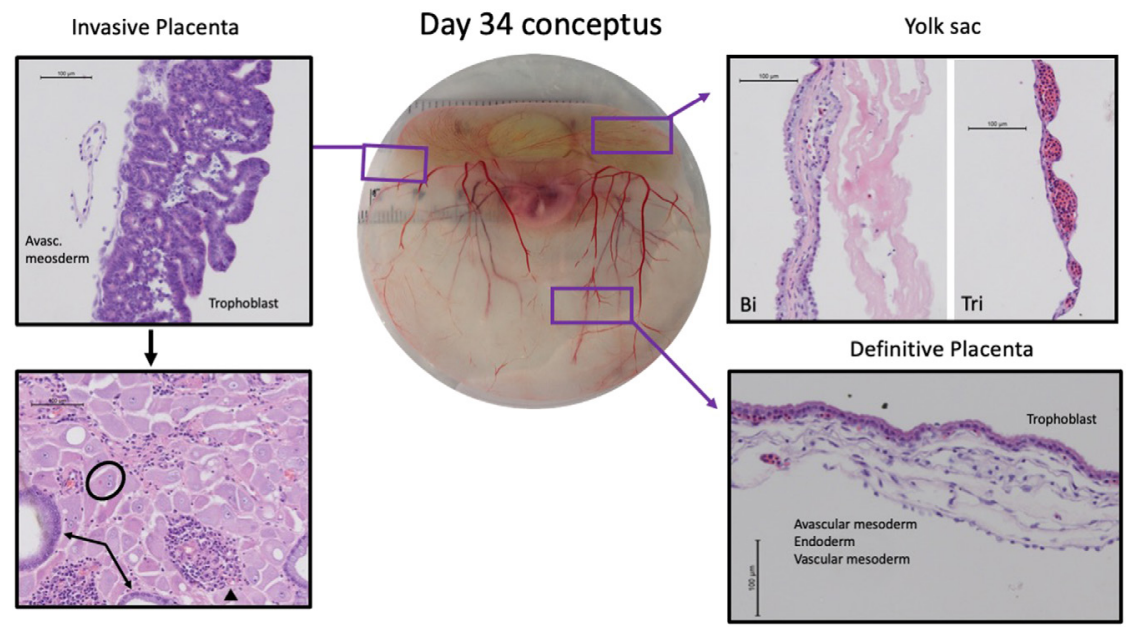

Figure 2 Day 34 equine conceptus highlighting the location of the chorionic girdle (invasive placenta, upper left), yolk sac (upper right) and allantochorion (definitive placenta, lower right). Hematoxylin and eosin-stained histological sections demonstrate the cellular composition of each membrane at day 34 , including the layers that contribute to each tissue. The chorionic girdle cells invade into the endometrium around day 36-38 to form the endometrial cups (lower left histological image) with an arrow highlighting endometrial glands, a circle demonstrating a binucleate cell and an arrowhead showing a cluster of lymphocytes. Scale bar $=100 \mu \mathrm{m}$. 
and higher read counts was selected. All non-reproductive tissues were selected from the functional annotation of animal genomes project as all tissues sequenced were derived from two young, healthy individuals; tissues selected included major internal organs as well as those with a peripheral reproductive function, including lung, liver, kidney, cerebellum, adrenal gland, skin and adipose. A full list of tissues analysed is described in Table 1, with a total of 78 samples representing 20 different tissues/conditions being ultimately analysed.

Sequencing quality from FASTQ files was assessed using FASTQC, with bases with a Phred score $<20$ were trimmed using Trim Galore. Trimmed FASTQ files were mapped to EquCab3.0 (Kalbfleisch et al. 2018) using STAR-2.5.2b, then annotated with Cufflinks-2.2.1 using the Ensembl v 95 Equus caballus annotation file. All programs were run using the default settings unless otherwise specified. To better control for inter-study variability, quantification was performed via transcripts per million (TPM).

As there is necessarily a great deal of variability in sequencing techniques and library preparation between samples, we chose not to rely strictly on differentially expressed genes for any part of our analyses, instead use much more stringent conservative criteria to identify genes of importance. To be defined as highimpact genes, both high expression (>100 TPM) and large differences across tissues ( $>100$ fold-change) were required. To identify placental-enriched genes, moderate to high placental expression (>10 TPM) combined with low expression in all other studied tissues ( $<1.5$ TPM) was the criteria.

\section{Gene expression in placental lineage formation and placental membranes throughout gestation}

\section{Trophectoderm}

The equine embryo is retained in the oviduct between 5.5 and 6.5 days, entering the uterus as a morula or early blastocyst. The first report of TE gene expression using an array or NGS technology is at day 8, coinciding with at least 36-h exposure to the endometrial environment. Equine embryonic stem cells are totipotent cells whose initial differentiation results in the formation of a placental lineage (TE) and embryonic lineage (inner cell mass; ICM), with the TE ultimately contributing to all four types of placental membrane in the horse (Fig. 1). Therefore, not surprisingly, gene expression in day 8 blastocysts between TE and ICM is overlapping, with the TE expressing 705 unique transcripts and an additional 10,364 transcripts in common with the ICM (Iqbal et al. 2014). The TE is defined by enriched expression of transcription factors such as CDX2, GATA2, GATA3, TEAD4, ELF3 and TFAP2A (lqbal et al. 2014), many of which are also genetic signatures in mouse, human and bovine TE (Posfai et al. 2019). Similar to early TE of human embryos, day 8 equine TE also express the pluripotency markers, POU5F1 (Choi et al. 2009) and $C D X 2$, a pattern that also distinguishes them from mouse embryos which exclusively express these genes in the ICM or TE respectively (Horii et al. 2016). Meta-analysis demonstrated that many key genes used to define ICM, TE and primitive endoderm (Iqbal et al. 2014) are also expressed in a broad range of tissues (Table 2).

The most highly expressed transcription factor in equine TE is GATA3 (Iqbal et al. 2014), with the metaanalysis indicating that expression is sustained throughout equine placental development (Table 2) consistent with high levels of expression observed in human placentae (Saben et al. 2014). Whilst in vitro generated cell lines such as induced TE derived from equine umbilical cord matrix mesenchymal stem cells show a similar gene profile to ex vivo TE, they importantly lack expression of GATA3 (Reinholt et al. 2017). It is important to note

Table 1 Equus caballus-derived sequencing data used in meta-analysis.

\begin{tabular}{|c|c|c|c|c|}
\hline Sample & Replicates & Library Prep & SRA identifier & Reference \\
\hline Adipose & 2 & PolyA-PE & ERP108802 & Burns et al. (2018) \\
\hline Adrenal cortex & 2 & PolyA-PE & ERP108802 & Burns et al. (2018) \\
\hline Cerebellum & 3 & Ribo-depleted-PE & SRP082342 & Mansour et al. (2017) \\
\hline Chorioallantois - 45 days & 4 & PolyA-PE & SRP127170 & Dini et al. (2018) \\
\hline Chorioallantois - 4 months & 4 & PolyA-PE & SRP219950 & Loux et al. (2019b) \\
\hline Chorioallantois - 6 months & 4 & PolyA-PE & SRP219950 & Loux et al. (2019b) \\
\hline Chorioallantois - 10 months & 4 & PolyA-PE & SRP219950 & Loux et al. (2019b) \\
\hline Chorioallantois - 11 months & 4 & PolyA-PE & SRP219950 & Loux et al. (2019b) \\
\hline Chorioallantois - post-partum & 4 & PolyA-PE & SRP219950 & Loux et al. (2019b) \\
\hline Chorionic girdle & 4 & CDNA-SE & SRP011379 & Wang et al. (2012) \\
\hline Endometrium - diestrus & 4 & PolyA-PE & SRP136284 & Scaravaggi et al. (2019) \\
\hline Inner cell mass (ICM) & 3 & CDNA-SE & SRP031504 & Iqbal et al. (2014) \\
\hline Kidney & 3 & CDNA-PE & SRP017611 & Fushan et al. (2015) \\
\hline Liver & 2 & PolyA-PE & ERP108802 & Burns et al. (2018) \\
\hline Lung & 2 & PolyA-PE & ERP108802 & Burns et al. (2018) \\
\hline Ovary & 2 & PolyA-PE & ERP108802 & Burns et al. (2018) \\
\hline Oviduct & 20 & PolyA-PE & SRP064530 & Smits et al. (2016) \\
\hline Skin & 2 & PolyA-PE & ERP108802 & Burns et al. (2018) \\
\hline Testes & 2 & PolyA-PE & SRP126383 & Janečka et al. (2018) \\
\hline Trophectoderm & 3 & CDNA-SE & SRP031504 & lqbal et al. (2014) \\
\hline
\end{tabular}

SRA, sequence read archive. 


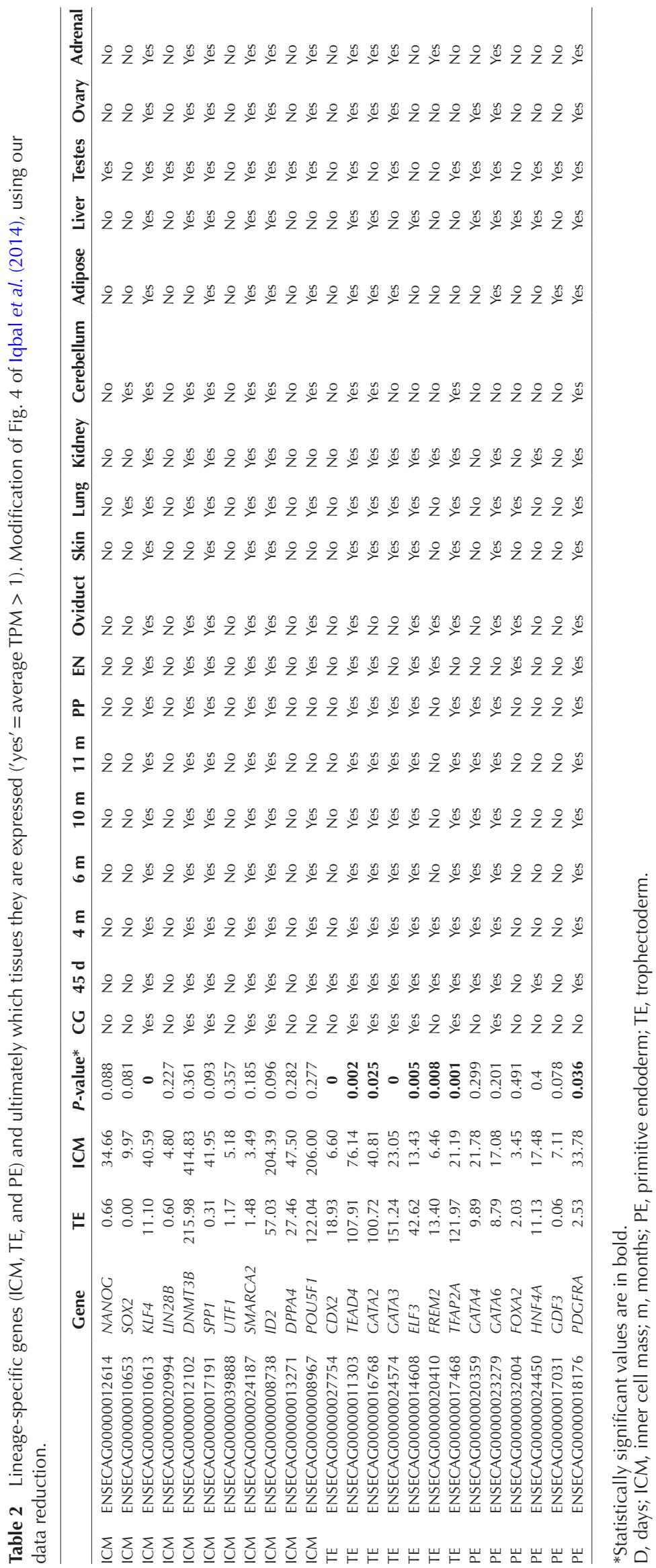


that many of these markers, whilst enhanced, are not always unique to the trophoblast lineages (Fig. 1 and Table 2). TEAD4, GATA2, ELF3 are also expressed in the endometrium and are thus unsuitable for differentiating between these two tissues. Two markers with the most enriched expression in placental tissues are CDX2 and TFAP2A. CDX2 is expressed in early TE (day 8) and chorionic girdle cells (days 35-36), but meta-analysis suggests not chorioallantois (45 day+) or other tissues, although it should be noted the meta-analysis did not include equine intestinal tissue known to express CDX2 in other species. CDX2 is a homeobox transcription factor that has been studied extensively in the context of its role in maintaining stemness of trophoblast stem cells. More recent work suggests that it also plays a role beyond these early events. In cows, CDX2 maintains expression in trophoblast post-implantation to at least day 20 where it activates IFNT expression via binding to the proximal promoter and inducing histone acetylation (Ezashi \& Imakawa 2017). In human placenta, CDX2 expression in villous cytotrophoblast remains strong at week 5 of gestation at the level of the chorionic plate but is absent in trophoblast nuclei of syncytial trophoblast and proximal cell column trophoblast suggesting it is lost as differentiation progresses (Horii et al. 2016, Soncin et al. 2018). Indeed, CDX2 expression drops linearly between week 5 and week 18 , by which time there are very few positive cytotrophoblast (Horii et al. 2016). The role of $C D X 2$ in the equine placenta is not known, but given the expression pattern here restricted to TE and chorionic girdle tissue, both tissues possessing trophoblast with stem cell characteristics, it likely primarily relates to maintaining trophoblast stem cells.

TFAP2A was highly expressed in all placental tissues examined to date, with low expression in testes and kidney and moderate expression in skin (Table 2). Epigenetic markers such as DNMT3B, whilst highly expressed in ICM, are also abundant in TE (lqbal et al. 2014, Table 2). DNMT3B is the major DNA methyltransferase regulating DNA methylation during development, so not surprisingly it is expressed in the yolk sac to at least 19 days (Gibson et al. 2017) and chorioallantois throughout gestation but minimally in adult tissues (Table 2).

\section{Yolk Sac}

The yolk sac first forms around day 8 when a layer of endoderm starts to underlay the TE resulting in the primitive bilaminar yolk sac wall (Figs 1 and 2). Around day 12 , the mesoderm starts to migrate between these layers providing the connective tissue and vasculature to form the trilaminar yolk sac (Figs 1 and 2), which ultimately transitions to the vascular yolk sac between days 18 and 20, a process that is comprehensively described in previous works (Betteridge et al. 1982, Enders et al. 1993). There are no published studies of global gene expression in either the bi- or tri-laminar yolk sac, although the transcriptome of whole conceptuses between days 8 and 14 has been reported (Klein \& Troedsson 2011).

A number of small studies have investigated gene and protein expression of select molecules proposed to be important to yolk sac functions, though most do not differentiate between the bi- and tri-laminar layers due to difficulties with dissection. Examples of key genes expressed in the yolk sac include maternally (GRB10, H19, IGF2R and PHLDA2) and paternally (DIO3, IGF2, INSR, PEG3, PEG 10, NDN and SNRPN) imprinted genes, epigenetic regulators such as DNA methyltransferases (DNMTs) and growth factors and related molecules (VEGFA, FLT and KDR) (Gibson et al. 2017). Many of these genes increase in expression in the developing yolk sac where they are likely to play important roles in sensing the environment and/or regulating the growth of the early embryo or yolk sac itself (Gibson et al. 2017). Yolk sac endoderm and trophoblast cells also express amino acid transporters such as SLC2A1 (Gibson et al. 2018), a glucose transporter acting to nourish the earliest stages of embryonic development. By day 14-16, yolk sac is hormonally active, expressing a high level of P450 aromatase (CYP19A1; (Walters et al. 2000)), ESR2 (Rambags et al. 2008) and 17BHSD (Raeside et al. 2009) as well as PGF2A and PGE (Stout \& Allen 2002) and the oxytocin receptor (Budik et al. 2012) indicating the yolk sac trophoblast actively regulates oestrogen and prostaglandin metabolism and bioactivity.

\section{Amniotic membrane}

The amnion first develops around day 16, resulting from folding of the chorion (ectoderm and avascular mesoderm layers) around the embryo (Fig. 1). Fusion is complete by 20 days (Acker et al. 2001), immediately prior to the loss of the capsule. There has been interest in the amnion at term as it is commonly used for wound healing, including treatment of corneal ulceration (Lassaline et al. 2005). Although the mechanism of action is unclear, it has been proposed to act through stem cell-associated factors (Seo et al. 2013), and/or through microvesicles containing anti-inflammatory miRNAs, capable of modulating interleukin signalling (Lange-Consiglio et al. 2018). Whilst the proteome of amnion has been described, including lumican and dermatopontin which are believed to aid in corneal membrane healing (Galera et al. 2015), very little is otherwise known about amniotic gene expression.

\section{Chorionic girdle}

The chorionic girdle has been more extensively characterised than any of the other early equine placental membranes (Brosnahan et al. 2012, Wang et al. 2013, 
Read et al. 2018a). At day 27, the tissue is initially composed of a single layer of vascular mesoderm cells which sit underneath a single layer of tall columnar trophoblast (Figs 1 and 2) (Antczak et al. 2013). In the ensuing days, the trophoblast cells start to rapidly proliferate (Gerstenberg et al. 1999) forming a stratified columnar epithelium which by day 34 involves multiple layers of trophoblast which are thrown into folds (Fig. 2). The trophoblast morphology undergoes extensive changes over this period converting from primarily uninucleate cells with a small cytoplasmic diameter to majority binucleate cells with a large cytoplasm (Antczak et al. 2013). Therefore, any study of gene changes in the chorionic girdle must be considered alongside these profound changes in tissue composition and will most certainly reflect the proportion of uni-/bi-nucleate cells present. Not surprisingly, this tissue transformation is accompanied by dynamic changes in the transcriptome of the chorionic girdle with 1625 genes differentially expressed during chorionic girdle development compared with the essentially unaltered gene profile of the adjacent chorion over the same 7-day period (Read et al. 2018a). The majority of the genes rapidly increase or decrease in expression over this period but of interest is a group of 83 genes that are transiently increased at days 30/31 (Read et al. 2018a) and may well be critical in controlling the rapid proliferation and differentiation of the tissue. These include spliceosome-related genes, as well as FGF10, a governor of trophoblast movement in ewes (Yang et al. 2011) and cell cycle regulators such as CDC16, an APC complex member that governs exit from mitosis.

The chorionic girdle distinguishes itself from other trophoblast tissues in its high expression of major histocompatibility complex (MHC) class I (Bacon et al. 2002), discussed in more detail below. For decades, chorionic girdle trophoblast has been thought of as an immunologically active tissue (Noronha \& Antczak 2012) that stimulates antigen-specific B cell responses (Antczak \& Allen 1989), attracts a T cell infiltration characterised by immunosuppressive Treg cells (de Mestre et al. 2010, Noronha \& Antczak 2012) and modulates lymphocyte function (Flaminio \& Antczak 2005). Indeed, chorionic girdle trophoblast can be transplanted across allogeneic barriers into the vulva of non-pregnant mares and survive for up to 3 months (de Mestre et al. 2011) as well as resist secondary immune responses (Brosnahan et al. 2016) further demonstrating the powerful immunological properties of the cells. Chorionic girdle trophoblast produces cytokines TNF (Grünig \& Antczak 1995) and IL-22 (Brosnahan et al. 2012), the latter likely involved in mucosal immunity and repair of epithelia during the invasion process (Brosnahan et al. 2012). Chorionic girdle cells are also hormonally active; between days 27 and 34, there is a rapid and substantial upregulation of the chorionic gonadotrophin alpha and luteinizing hormone beta
$(L H B)$ (previously $C G B$ ) subunits facilitating equine chorionic gonadatrophin (eCG) expression (de Mestre et al. 2009), ultimately comprising the first and seventh most abundant protein-coding genes in chorionic girdle respectively (Fig. 2). Expression of $L H B$ is regulated directly by transcription factors GCM1 and ELF5, which show a similarly dramatic upregulation (Read et al. 2018b).

Growth factors comprise another abundantly expressed group of genes in the chorionic girdle and are believed to act in an autocrine manner to coordinate the development of the chorionic girdle along with spatial coordination of adjacent tissues such as the allantochorion (Fig. 2). Read et al. (2018a) showed an upregulation of ERK1/2 activity in ex vivo day 30 chorionic girdle tissue suggesting this pathway is active corresponding to a period when in vivo trophoblast proliferation is maximal (Read et al. 2018a), although in vivo regulation of ERK1/2 and AKT1 pathways is not known. Curiously HGF, $E G F$ and FGF2 are not expressed in any appreciable quantities in chorionic girdle tissue or allantochorion between days 45 and term, although EGF is present in the adjacent endometrium and may be acting in a paracrine manner (Allen et al. 2017, de Ruijter-Villani et al. 2013). FGF7 is one of the top ten most highly expressed genes in day 31 chorionic girdle trophoblast (Read et al. 2018a) with expression sustained at day 34, and coinciding with expression of its receptor, FGFR2 (Read et al. 2018a). IGF2 (and less so IGF1) and its receptors $I G F 1 R$ and $I G F 2 R$ along with a number of the insulin-like growth factor-binding proteins (IGFBPs) are highly expressed by both chorionic girdle tissue and allantochorion (Lennard et al. 1995; Fig. 2). Although placental IGF signalling is well defined in other species (Sferruzzi-Perri et al. 2017) where it drives proliferation and migration of primary trophoblast cells, functional studies are urgently needed to define the role of these placentally derived growth factors in equine placental development and expansion (Fig. 2).

Whilst mechanistic studies are lacking for these growth factors, TGF $\beta$ ligand BMP4 has been shown to regulate differentiation of chorionic girdle trophoblast acting via SMAD1/5 (Cabrera-Sharp et al. 2014). BMP4 was found to be expressed by both the chorionic girdle itself and adjacent endometrium suggesting both autocrine and paracrine functions (Cabrera-Sharp et al. 2014) (Fig. 2). SMAD2 signalling is also active in primary chorionic girdle trophoblast, supporting the possible importance of other TGF $\beta$ ligands in regulating early placental development (Cabrera-Sharp et al. 2014).

The binucleate terminally differentiated chorionic girdle cells dislodge from the conceptus around 36 days and remain viable in the endometrium until approximately 100 days. The exact mechanisms that result in the death of the endometrial cup trophoblast are not definitively shown, although it is assumed 
to be due to either CD4 and CD8+ lymphocytemediated destruction or via pre-programmed cell death. Not surprisingly, the endometrial cup trophoblast shares expression of a number of genes with mature chorionic girdle cells, but equally, gene expression is also modulated by the new endometrial environment (Aleksic et al. 2016). The best characterised example is expression of MHC class I, which is downregulated in binucleate trophoblast following the establishment of the endometrial cups then subsequently upregulated late in the lifespan of the cells (Antczak \& Allen 1989). Pregnancy-specific glycoproteins also show complex regulation between these two environments (Aleksic et al. 2016) with some pregnancy -specific glycoproteins genes exclusively expressed in chorionic girdle tissue (CEACAM44), the endometrial cups (CEACAM48) or both tissues (CEACAM49).

\section{Chorioallantois (allantochorion)}

The allantois originates from the posterior end of the embryonic gut and develops rapidly until it surrounds the embryo and fuses with the chorion to form the allantochorion that will become the main placenta in the mare (Fig. 1). At 45 days, the allantois has completely replaced the yolk sac, which has been incorporated into the elongating umbilical cord. The trophoblast cells of the newly formed allantochorion are cuboidal to low columnar (Fig. 2) and remain as a single layer of cells that are in close apposition with the endometrial cells with villi not forming until 50 days. Although little is known about global gene expression in the early stages of allantochorion formation, expression of growth factors and their receptors is well characterised, as in chorionic girdle. Allantochorion trophoblast expresses EGFR from as early as days 25-30 with expression dramatically upregulated by days 35-40 (Allen et al. 2017). Other growth factors VEGFA, FLT1 and KDR are all expressed by days 25 and 38 (Allen et al. 2007), with expression maintained throughout gestation (Loux et al. 2019b). There is a predominance of VEGF family members in allantochorion (Loux et al. 2019b), with VEGFA showing significant expression even in 8 day TE (Iqbal et al. 2014) while VEGFB and VEGFC are expressed by 45 days. Of the growth factors studied, the IGF family is the most abundant in early gestation and is discussed further below.

Overall, the 45-day allantochorion shows signs of being in a transitory state between the largely selfreliant embryo and the mature fetoplacental unit. Metaanalysis revealed 376 genes are up-regulated more than 100-fold between 8-day TE and 45-day allantochorion, with $91 \%$ of these expressed at minimal levels in 8-day TE $(<1$ TPM), confirming major regulatory changes during this period (Wang et al. 2012, lqbal et al. 2014). In comparison, only 17 genes had 100-fold higher expression at 4 months vs 45 days (Wang et al. 2012, Loux et al. 2019a). Although far more genes showed increasing expression from TE to 45-day allantochorion, a few genes declined significantly in this time frame. Among these, most noticeable is a steep decline in pluripotency factors POU5F1, LIN28A and ESRRB as the placenta begins to mature and stabilize. Furthermore, waning expression of metabolism-related genes (MIOX, $A C S L 6, T T C 39 B)$ is seen as implantation occurs and the embryo increasingly begins to rely more heavily on nutrients from maternal circulation. Lastly, multiple histone transcripts (HIST2H2BF, HIST1H1A, HIST1H1B, HIST1H1E) show decreasing expression, with novel transcripts and small RNAs such as eca-miR-9173, snoRNA33 and RF02271 making up the majority of remaining down-regulated transcripts.

Steroidogenesis-related transcripts tell a similar story of a transitioning tissue, as well as providing hints into tissue physiology. For example, the 45-day allantochorion produces high levels of the enzymes required for cholesterol synthesis as well as STAR, CYP11A1 and CYP17A1, suggesting that, as in the rabbit, this early tissue is able to effectively synthesize cholesterol de novo, as well as mediate conversion to the $\Delta 5$ androgen DHEA (Loux et al. 2020). A strong correlation exists between these placental enzyme transcripts and DHEAS in maternal circulation $(r>0.978 ; P<0.001$; Legacki et al. 2019), lending credence to a placental origin for DHEAS. This is in contrast to later gestation ( $\geq 4$ months) when DHEA synthesis switches primarily to the fetal gonad, corresponding with an increase in unsulfonated DHEA in maternal circulation (Legacki et al. 2017).

Enzymes present later in the steroidogenic pathway, including HSD17B1, HSD 17B2, HSD3B2 and CYP19A1 are present across gestation, albeit at relatively lower levels in the 45-day allantochorion than later gestational ages (Loux et al. 2020). These data are consistent with the work from the groups of both Raeside and Sharp which found that equine embryos produce estrogens in extraembryonic membranes as well as in the ICM (Raeside et al. 2012) as early as 12 days of gestation (Zavy et al. 1984). As the fetoplacental unit continues to mature (45 days to 4 months), additional endocrine transcripts show significant up-regulation including AKR1C1, AKR1C23-like, PTCDS, SULT1E1, OXTR, NR4A1, GSTA3 and SULT1A1 (Loux et al. 2020).

The fetomaternal placental unit appears to be fully mature by 4-month gestation, although the exact point of maturation can only be defined as $>45$ days and $\leq 4$ month gestation. Maturation here is defined by a lack of significant changes in gene expression (as compared to 6-month allantochorion); false discory rate (FDR) $P$-value < 0.05; (Loux et al. 2019a)). These two periods also mark a significant shift in tissue structure: a single layer of trophoblast in apposition with endometrium is observed at around day 45 (Fig. 2), whilst by 4 months, 
microcotyledons and villi have formed. Between 80 and 120 days is also the approximate time of the luteoplacental shift, when pregane synthesis has shifted away from progesterone (P4) synthesis by the corpus lutea and moved primarily to $5 \alpha$-dihydroprogesterone (DHP) synthesis by the allantochorion (Conley \& Ball 2019). By 10 months, gene expression changes are again becoming apparent, with transcription starting to shift towards parturition and away from steroidogenesis as noted by a decrease in intracellular cholesterol transport transcripts (ABCA1, ABCG1, LRP6, OSBP, STAR, NPC1, NPC2; (Loux et al. 2019a)) and steroidogenic enzymes themselves, most notably CYP19A1 (Loux et al. 2020). Evidence for the balance of steroidogenesis between the allantochorion and endometrium is apparent at this time, as expression of most steroidogenic enzymes continues to increase in the allantochorion, while concurrently declining in the endometrium. This phenomenon is particularly pronounced for the $\Delta 4 \rightarrow \Delta 5$ steroidogenic enzymes HSD17B1, HSD17B2, HSD3B2 and GSTA3 but is also evident in downstream pathway enzymes such as $5 \alpha$-reductase $S R D 5 A 1$, as well as AKR1C1, SULT1E1 and SULT1A1 (Loux et al. 2020).

Preliminary evidence suggests that gene expression levels may be both correlatory and predictive of function. In addition to the tight correlation between placental CYP17A1 and maternal DHEAS described above, additional select transcripts were significantly correlated to their expected steroid product in maternal circulation (Fig. 3). For example, CYP19A1, the transcript for P450 aromatase, was correlated with maternal estrone sulphate levels $(r=0.661)$, while $S R D 5 A 1$ (5a reductase) was correlated with maternal 5a-dihydroprogesterone $(r=0.552)$.

Non-coding RNAs such as miRNAs are also indisputably important in allantochorion development. In early equine pregnancy, miRNA have been proposed to be involved in maternal recognition of pregnancy (Klohonatz et al. 2016). Orthologous members of the placental-specific C14MC cluster have been shown to be up-regulated in maternal circulation during pregnancy (Dini et al. 2019), with these and other miRNA shown to change significantly during late pregnancy and placental infections (Loux et al. 2017), with both tissue-level and circulatory miRNAs showing distinct expression patterns based on the stage of disease (Loux et al. 2019b).

Due to the bulk tissue approaches used to date for the above studies, remarkably we don't know yet how these changes relate to the marked change in tissue composition of the allantochorion across gestation, or whether any of these genes are trophoblast specific, or reflect changes to the phenotype of the trophoblast cells themselves. Application of single-cell transcriptomic assays is therefore a must if we are to tackle this complexity and identify the upstream regulators of normal allantochorion placentation in the mare.
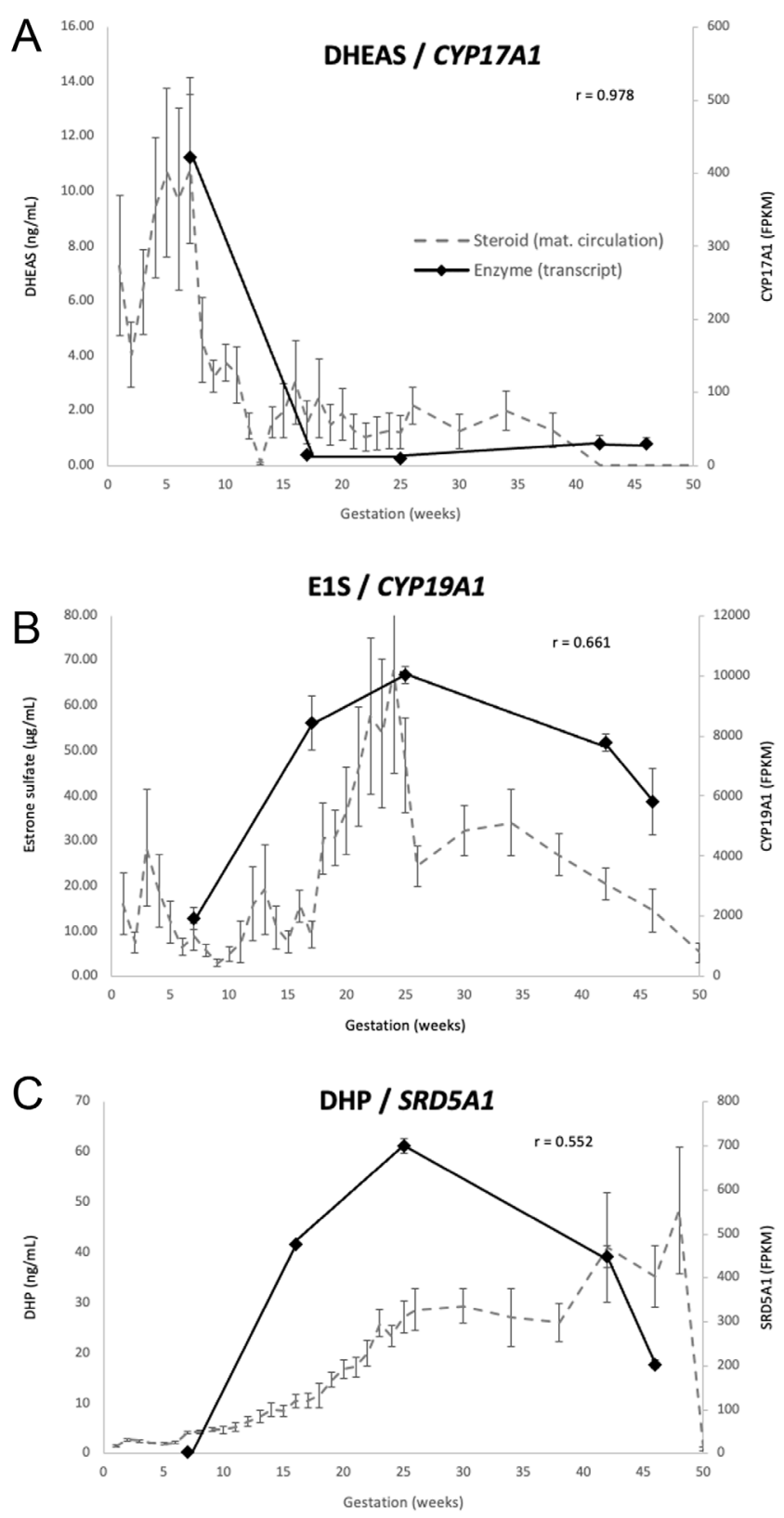

Figure 3 Correlation between circulating steroids and placental gene expression. Concentration of steroids in maternal circulation is indicated by dashed grey line (- - ), while placental transcript levels are indicated by black circles $(\mathbf{)}$ ). (A) Correlation of DHEA sulphate (DHEAS) to CYP17A1; (B) correlation of estrone sulphate to CYP19A1 (aromatase); and (C) correlation of $5 \alpha$-dihydroprogesterone (DHP) to SRD5A1 (5-alpha reductase 1). Serum steroid data obtained from Legacki et al. (2019) (DHEAS and E1S) and Legacki et al. (2016) (DHP). The 50-week time point represents post-partum serum samples. Error bars indicate S.E.M. All correlations were significant $(P<0.001)$.

\section{Term placentae}

Literature addressing gene expression changes at parturition is slim, likely due to the difficulty in obtaining late gestational samples for comparison 
purposes. Further, most of what we have learnt about the term placentae has been gleaned from data on control placentae for pathologies such as retained fetal membranes (Jaworska et al. 2021). A full review of the most important genes found to be responsive to pathologies, environmental cues and mare factors can be found in Robles et al. (Robles et al. 2022).

There have been a few publications that have focused on gene expression in the non-pathological term placenta, such as work by Loux et al. (2020) which includes samples throughout gestation and postpartum, providing some insight into driving changes, including the endocrine changes discussed above (Fig. 3). In addition, we were able to use the serial data set from Loux et al. (2019a) to confirm and expand hypotheses from other works. Circadian rhythm genes (CLOCK, CRY1, CRY2, PER1, PER2) were identified in equine placenta by Parsons Aubone et al. (2020); however, they were not able to find a correlation between relative expression and gestational length. By using the serial data set, we were able to identify an increase in CRY1, CRY2 and PER 1 during late gestation, with PER1 increasing over $400 \%$ between 11 months and postpartum placentae. These data also confirmed strong expression of MHC-I genes at parturition (Rapacz-Leonard et al. 2018), with expression notable in allantochorion from as early 4 months, albeit at all gestation ages at a level that remains well below that observed in the chorionic girdle. As well, it supported work by Oddsdóttir et al. (2011) finding an increase in MMP2 and -9 transcript in the postpartum placenta compared with 11-month allantochorion (Oddsdóttir et al. 2011).

\section{High-impact placental genes}

\section{Genes that differentiate early placental tissues trophectoderm, chorionic girdle and allantochorion}

Comparison of gene expression in placental lineages allows for identification of important candidate genes responsible for the development and function of individual tissues, but due to the large number of genes identified, it can be difficult to characterise the most essential. In early development, the TE contributes to the chorion trophoblast which in turn gives rise to both the chorionic girdle and allantochorion. Ergo, we utilize the meta-analysis to identify a subset of predicted 'high-impact' genes to better define the transition from TE to allantochorion and chorionic girdle. These genes were both highly expressed (TPM > 100) and highly up-regulated (fold change $>100$ ) between the common derivative tissue, 8-day TE, and one or both of the two main tissue lineages of the equine placenta, chorionic girdle (day 33) and allantochorion (45 days and 4 months). This identified a total of 182 genes, many of which showed significant changes in expression among multiple tissues and time points (Supplementary Table
1 , see section on supplementary materials given at the end of this article). Notably, only half of these were identified as protein-coding genes, with the remainder classified as novel or ncRNA. This suggests that changes in ncRNA may be as critical to successful early embryonic development and placental differentiation as the better-studied changes in protein-coding genes, although it should be remembered that differences in library preparation between the TE and CG (cDNA, single-end reads) and allantochorion tissues (Poly- $A$ selection paired-end reads) may introduce bias. A direct comparison of gene expression between chorionic girdle and allantochorion for a number of key placental processes reveals distinct roles, chorionic girdle predominantly enriched for gonadotrophin expression in line with its function of eCG production as well as genes involved in antigen presentation (Fig. 4), whereas allantochorion showed relatively higher expression of angiogenic, chemotaxic, extracellular matrix (ECM) and focal adhesion genes.

During the transition from 8-day TE to 45-day allantochorion, most genes were up-regulated (Supplementary Table 1); however, there was a subgroup which was down-regulated, including pluripotency factors POU5F1, ESRRG and LIN28A. Amino acid transporter SLC36A2, known to be highly upregulated in equine endometrium in early pregnancy, was also down-regulated between TE and 45 days (Klein et al. 2010) possibly indicating a difference in embryonic metabolism. In addition to the increase in endocrinerelated transcripts described earlier, there is a clear up-regulation in expression of ECM-related factors, including a number of collagen family members (Supplementary Tables 1 and 2). Remarkably, this dramatic collagen up-regulation seems to be much more prevalent in the 45-day allantochorion than the chorionic girdle (Fig. 4), perhaps a reflection of the more temporary nature of the chorionic girdle cells. This discrepancy extends into other ECM-related transcripts including collagen fibril organizer, lumican (LUM) and embryo adhesion factor, thrombospondin (THBS1; (Kolakowska et al. 2017)). Fibrinogen has been suggested to be involved in embryonic adhesion in an integrin-dependent manner (Grant et al. 2020); this hypothesis is well supported by our data as we identified not only $F G B$ but also many other focal adhesion and ECM proteins changing significantly here as well (Fig. 4).

In the transition from TE to chorionic girdle, a different pattern emerges. Although an up-regulation of both ECM and endocrine-related transcripts exists (Supplementary Table 1), the chorionic girdle cells also have an increase in transcripts related to ECM degradation (MFAP2) and autophagy (RAB17), presumably related to their invasive properties. Expression of the fetal haemoglobin subunit $H B E$ was primarily within the allantochorion throughout gestation, although transcription levels 


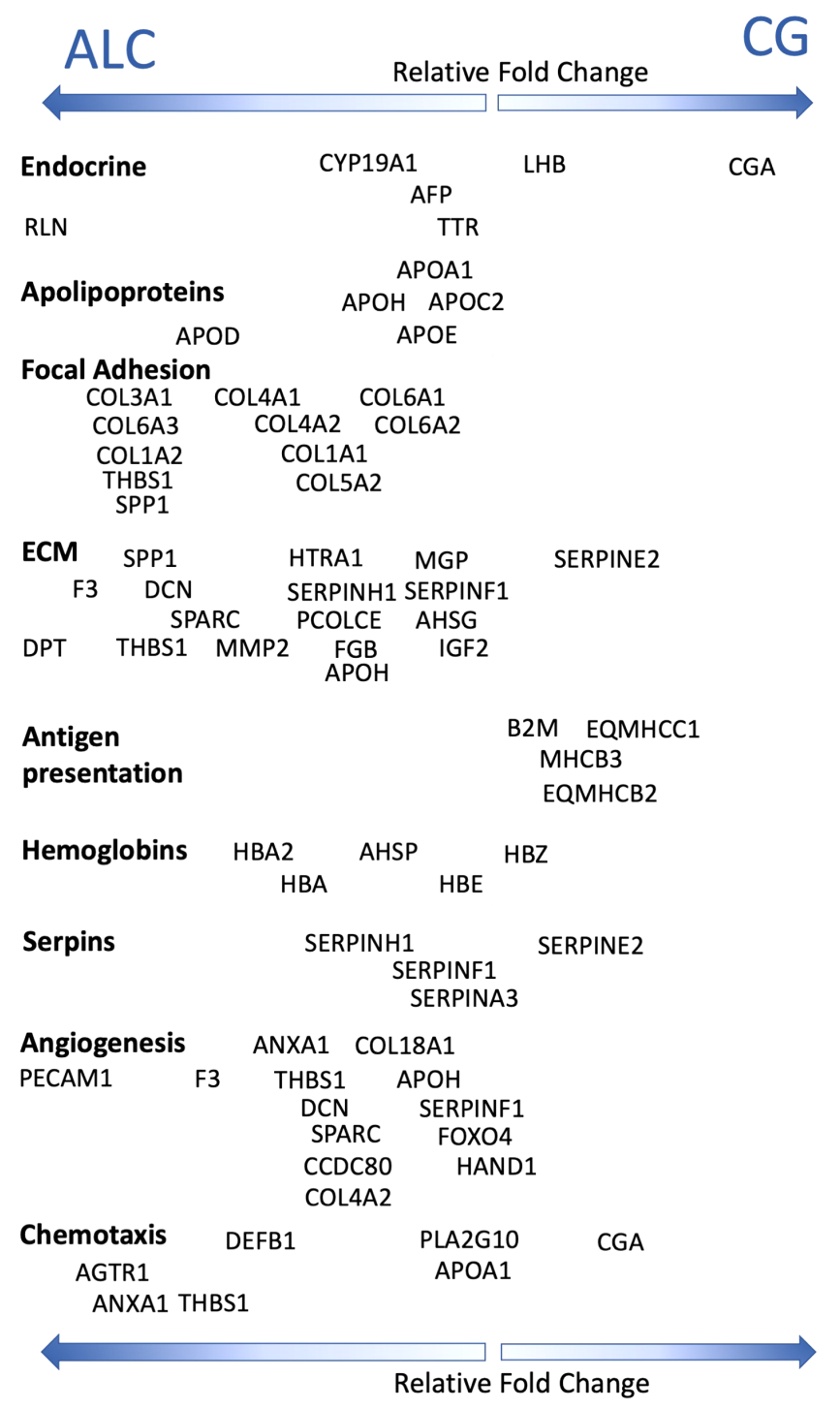

Figure 4 Functional comparison of high-impact genes in the allantochorion (ALC) and chorionic girdle (CG). Inclusion criteria include $>100 \times$ increase from 8-day TE and $>100$ TPM in either 45-day ALC or 34-day CG. Location along X-axis indicates relative fold-change between ALC and CG by category, with more distal localization indicating increasingly tissue-biased expression.

declined steadily until 11 months gestation. Of note, another fetal hemoblogin subunit (HBZ) showed the highest expression in chorionic girdle cells (Fig. 4 and Supplementary Table 2). Curiously, no expression of $H B Z$ is seen in either allantochorion (> 4 months) or fetal liver. This differs significantly from humans where $H B Z$ is produced in the fetal liver after $\sim 8$ weeks of gestation. The lack of $H B Z$ production in equine fetal liver is likely to reflect species differences, as another fetal liver gene, $A F P$, is transcribed in the early placenta (chorionic girdle and 45-day allantochorion), then shifts to the liver by 4 months gestation, similar to humans.

A number of apolipoproteins were identified as highimpact genes in early development, including APOA 1 ,
APOC2, APOE and APOM (Supplementary Table 1). Best known for their role in cholesterol transport, apolipoproteins have been shown to have a protective, anti-inflammatory effect in human placenta and may act to prime maternal endothelial cells for trophoblastic invasion (Charlton et al. 2017). Equine APOA1 and $A P O E$ are highly expressed in the early allantochorion and also found in chorionic girdle, with the equine allantochorion also expressing high levels of $A P O D$ throughout pregnancy. A subset of chorionic girdle and allantochorion samples (35-45 days) were found to produce an even wider range of apolipoproteins, including APOC2 and APOM (Fig. 4).

The IGF family plays a prominent role in early gestation; IGF2 is the most abundant growth factor in both chorionic girdle and allantochorion (45 days) and the only growth factor to be included in Supplementary Table 2. Several other IGF family members only fell just short of the 100 TPM threshold, including IGF2R and IGFBP2, 3, 5 and 7, making this family the most abundant in early equine placental tissue with expression levels increasing 50- to 6000-fold over 8-day TE. As in humans and mice, equine IGF2 is a paternally imprinted gene best known for driving fetal growth, while its receptor, IGF2R is maternally imprinted (Wang et al. 2013). However, a recent equine study (Dini et al. 2021) found that IGF1, $I G F 1 R$ and INSR are also paternally imprinted, while IGFBP4, a negative regulator of angiogenesis (Contois et al. 2012), is maternally expressed, speaking to a delicate balance of maternal and paternal regulation. IGFs also appear to be environmentally regulated; during negative asynchronous embryo transfer, extraembryonic expression is delayed but not dysregulated, a feature proposed to contribute to the resilience of equine embryos in an asynchronous uterine environment (Gibson et al. 2017). Whilst functional studies are lacking, IGF1 protein expression has been shown in microcotyledons at day 130 of pregnancy with expression decreasing over gestation and positively correlating with the number of proliferating trophoblast suggesting a possible role in promoting allantochorion and more specifically microcotyledonary development (Arai et al. 2006).

Next, we aimed to identify specific gene markers of differentiation that differed between allantochorion and chorionic girdle cells by identifying genes with $>100$ fold-change and >10 TPM in the tissue of interest. In total, there were 199 genes with enriched expression in chorionic girdle cells and another 80 with enriched expression in 45-day allantochorion (Supplementary Table 2). Although the majority of chorionic girdle genes were either novel genes or ncRNA, there were three protein-coding genes which had exclusive expression in chorionic girdle cells: FABP4, FXYD6 and PXMP2. FABP4 is the most highly upregulated gene in both day 30 and 31 chorionic girdle (Read et al. 2018a), suggesting expression is sustained for a good proportion of chorionic 


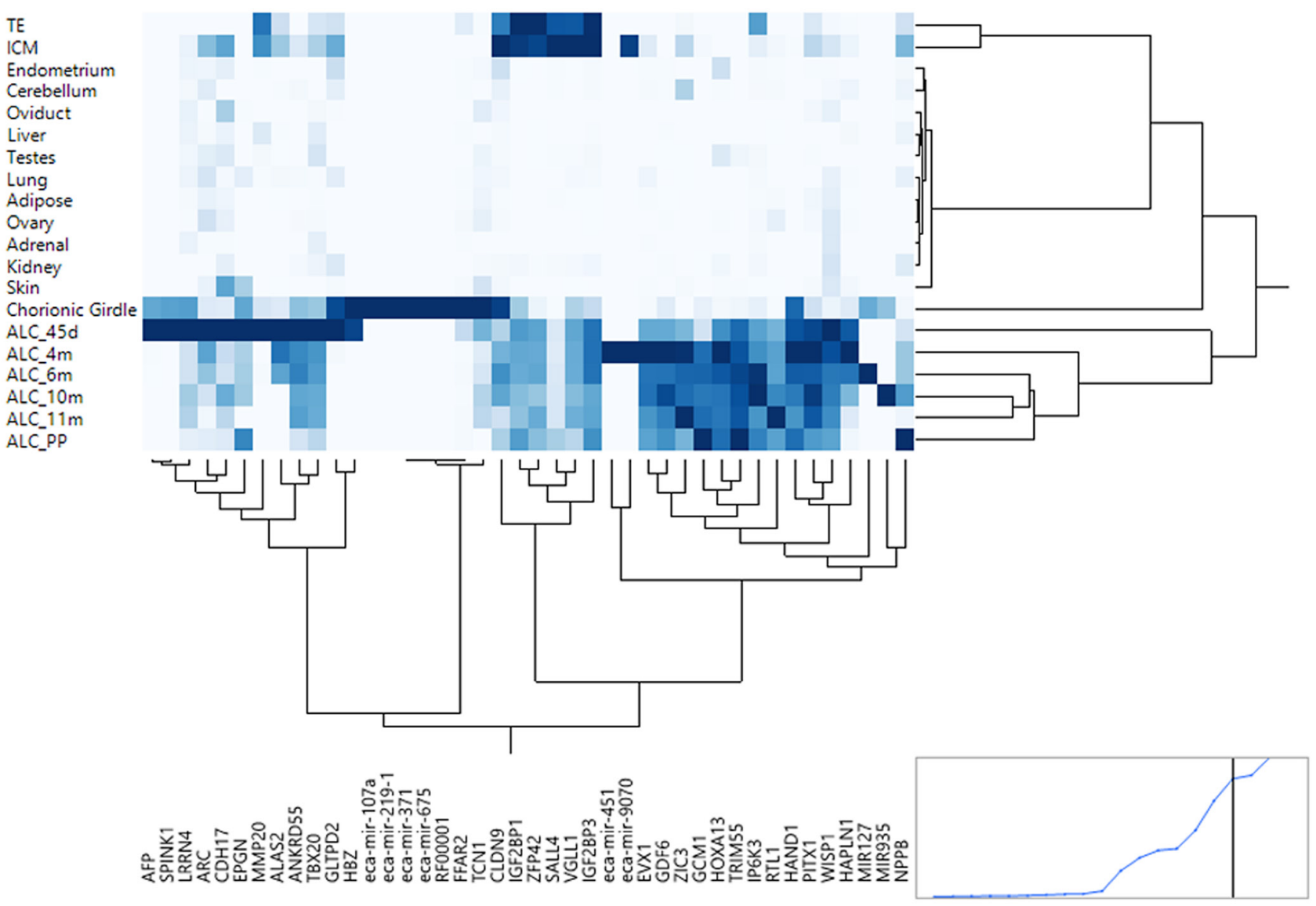

Figure 5 Expression of 42/77 high-impact placenta-enriched genes as defined as TPM $<1$ in non-placental tissues and TPM $>10$ in placental tissue(s). Trophectoderm (TE), inner cell mass (ICM), chorionic girdle (CG) and allantochorion between 45 days and 11 months, postpartum (PP) chorioallantois and diestrus endometrium (EN). Expression of an additional 35/77 transcripts with no assigned gene can be found in Supplementary Fig. 1.

girdle development. It is an excellent candidate gene to drive development of the chorionic girdle, having been found to promote trophoblast proliferation, migration and invasion in human trophoblast (Yan et al. 2016). The smaller total number of identified ALC-enriched genes contained a much higher number of protein-coding genes $(n=54)$, including SPAM1, LTF and HPGD, among others (Supplementary Table 2). We propose that these genes may be used as linage-specific markers to differentiate between these two closely integrated tissue lineages.

\section{Placental-enriched transcripts across pregnancy}

The placenta is a rapidly forming and expanding organ with diverse physiological functions, so it is not surprising that equine placental tissue expresses an array of genes in common with other tissues and is normally associated with processes such as epigenetic regulation, cell proliferation, differentiation, immunity and movement. Indeed, it is a commonly held view across species that the placenta expresses very few placental-specific genes as they would be a target for immunological attack by the mother's immune system. A anti-trophoblast antibody (102.1) that labels equine allantochorion and chorionic girdle trophoblast cells between day 12 and term has been widely utilized by researchers since the initial report (Oriol et al. 1993). The antibody labels an unknown antigen, with the original study suggesting it may be trophoblast specific as the antibody failed to label other cells in day 8 embryos as well as all 18 adult and 6 non-placental fetal tissues assessed (Oriol et al. 1993). There were two transcripts in our metanalysis that had an expression profile across placental and non-placental tissues that best matched this antigen distribution: Claudin 1 (CLDN1) and Iroquois-class homeodomain protein 4 (IRX4). IRX4 is a transcription factor with primarily nuclear expression in tumour and cardiac cells so is unlikely to represent the antigen detected by 102.1 which is mostly localized to the cell surface. Claudin 1 remains a strong candidate. It is highly expressed in human chorionic villous trophoblast (Zhang et al. 2021) and as a membrane protein and major contributor to tight junction complexes, it shows similar distribution 
to the antigen labelled by 102.1. Further work must be done to verify this hypothesis.

Lastly, to identify further genes of importance, we began by looking for placental-enriched genes $(>10$ TPM in placental tissue(s), <1 TPM in non-placental tissues) with no fold-change requirement, ultimately identifying 71 genes (Fig. 5). Four enriched genes (IGF2BP3, Zinc Finger Protein 42 (ZFP42), Vestigial Like Family Member 1 (VGLL1), Paired Like Homeodomain 1 (PITX1)) are expressed in all placental tissues examined to date (TE, chorionic girdle, allantochorion). IGF family member IGF2BP3 was predictably enriched, as the IGF system is known to be highly active in early placental development in many species (Sferruzzi-Perri et al. 2017), including equine as discussed above. Another placentally enriched gene, VGLL1 is a TEA family transcription factor found to have sustained co-expression with TEAD4 across gestation in human trophoblast, though VGLL1 appears absent in murine placenta (Soncin et al. 2018). The sustained expression of VGLL1 in equine placental tissues suggests the gene is not human-specific, highlighting the necessity of utilising comparative animal models of early placental development to complement work done in mice. ZFP42, aka Rex1, has long been used as a marker of pluripotent murine embryonic stem cells, although does not appear to be required for pluripotency itself (Masui et al. 2008). Expression patterns in equine placenta suggest a similar specificity and function. Lastly, PITX1, a GCM1 binding partner is enhanced across gestation (discussed further below; Read et al. 2018b).

A further four placental-enriched genes were expressed in all placental tissues except day $8 \mathrm{TE}$ (HAND1, TBX20, ANKRD55, GDF6). HAND1 is a well-characterised placental and cardiac transcription factor previously described in chorionic girdle and allantochorion (de Mestre et al. 2009) and also identified as a 'early developmental high-impact' gene when comparing just the three early placental tissues, $\mathrm{TE}$, chorionic girdle and allantochorion (Supplementary Tables 1 and 2). In mouse, HAND1-null animals have abnormalities in both trophoblast giant cell differentiation as well as cardiac development (Riley et al. 1998). Curiously, another of these enriched genes, $T B X 20$, is a transcription factor primarily known for its role in cardiac development (Ahn et al. 2000); however, TBX20 has not yet been studied in the placenta of any species. In the mouse, Hand 1 works in conjunction with other transcription factors including Stra13 and Gcm 1 to promote trophoblast differentiation, albeit towards different fates. While all three transcription factors drive cell-cycle exit, Hand 1 and Stra13 drive towards the giant trophoblast phenotype, while Gcm 1 is required for syncytiotrophoblast formation in the labyrinth region (Hughes et al. 2004). STRA13 (CENPX) is expressed at minimal levels in equine placenta and does not meet our definition of placental-enriched gene.
The transcription factor, GCM1, is rapidly induced in the chorionic girdle between days 27 and 34 (de Mestre et al. 2009, Read et al. 2018b), with maximal mRNA expression seen in the allantochorion from 4 months onwards. It is known to regulate eCG via direct binding to the LHB promoter (Read et al. 2018b) and possesses multiple functions in human trophoblast, suggesting further function in equine trophoblast are likely to exist as well. GCM1 protein expression is strong in the recently formed allantochorion (Read et al. 2018b), and gene expression persists in the allantochorion throughout gestation with the highest levels noted in term and postpartum allantochorion (Loux et al. 2019a) (Fig. 5). Due to the expression of GCM1 across a number of placental compartments, it is likely that its function is tightly controlled and at times modulated by the co-expression of GCM1 binding partners such as PITX1 and HOXA13 (Jolma et al. 2015), both also identified here as enriched genes (Fig. 5). PITX1 expression levels are negatively associated with GCM1: they decrease during chorionic girdle development right as GCM1 expression rises (Read et al. 2018b). This pattern is similarly observed in the allantochorion as GCM1 expression is maximal in postpartum allantochorion, while PITX is simultaneously decreased to its lowest levels (Loux et al. 2019a). These changes appear placental-specific as a number of other GCM1 binding partners are absent/show very low expression levels in equine placental tissues (ONECUT2, HOXA2, FIGLA, SPDEF, SOX2) (Loux et al. 2019a).

\section{Conclusion and final remarks}

Since the equine genome was sequenced in 2007, remarkable progress has been made in describing the genetic landscape of the maternal-fetal interface in the horse. Despite these numerous studies, it is clear that nearly all have used a bulk tissue approach so important questions remain regarding whether placental gene changes are reflective of changes in tissue composition and/or induction of genes in specific cells such as trophoblast. Further, full characterisation of equine trophoblast subtypes remains elusive. Moving forward, single-cell transcriptomics is pertinent if we are to appreciate the molecular events at the equine maternalfetal interface and to be able to address questions such as: what genes mark uninucleate vs binucleate cells in the chorionic girdle? Does eCG expression directly follow acquisition of binucleate morphology or are these decoupled events? What genes drive differentiation of trophoblast in the allantochorion?

Bulk tissue transcriptomics revealed both conserved and unique genes likely important in regulating equine placental development and function; however, significant gaps remain in our knowledge of the functional relevance of most of the genes and this must be a priority of the next decade. Exactly which of these genes and pathways will yield the most fruitful results is 
a difficult question. In order to address this, alongside the wider literature, we have looked holistically at all published transcriptomes of equine fetal membranes/ tissues to generate a more focused list of genes that act as signatures of the three key fetal tissues in early placental development (TE, chorionic girdle and allantochorion), as well as those that are highly enriched in the placentae compared to eleven other equine tissues. Whilst the strict criteria applied will have undoubtably meant some relevant genes will have been missed, the approach has provided a rich list of genes and gene families that warrant functional interrogation.

Wider researchers will be able to use this resource as a reference for designing future experiments, with certain genes and gene families highlighted as excellent candidates for more immediate mechanistic studies. For example, GCM1 is best known as a key gene of chorionic girdle tissue and regulator of CGB expression; however, our meta-analysis found it is widely expressed in equine chorioallantois and indeed the highest expression was found in term placentae. The function of GCM1 in chorioallantois is not known, although this expression along with its role in pathologies of pregnancy in other species suggests it should be a priority in any future studies. FABP4 was identified in meta-analysis as a CG-specific gene consistent too with previous data that found it to be the most highly expressed gene in days 30 and 31 chorionic girdle suggesting it has wide applications as a marker across chorionic girdle development with a functional role as yet undefined. Apolipoproteins were identified as high-impact genes of particular interest with dynamic expression of family membranes in early allantochorion, chorionic girdle or both. Shared expression of VGLL1 between horse and human but not rodent placenta is a reminder of the complex evolution of placental trophoblast cells.

These gene lists need to be supplemented with a greater understanding of the epigenetic landscape and interpreted alongside future proteomics and secretomic studies. Such studies are now key not only to inform researchers of key pathways relevant to understanding the complexity of normal placental development and its role supporting fetal health but also to unravelling novel targets that are modified by the environment and play a role in pregnancy pathologies (Robles et al. 2022).

\section{Supplementary materials}

This is linked to the online version of the paper at https://doi. org/10.1530/REP-21-0115.

\section{Declaration of interest}

The authors declare that there is no conflict of interest that could be perceived as prejudicing the impartiality of this review.

\section{Funding}

A M d M has received funding for work discussed in this review from Wellcome Trust, Alborada Trust, Thoroughbred Breeders Association. S L received funding for work discussed in this review from Kentucky Thoroughbred Owners and Breeders Association. P C P received funding for work discussed in this review from Institut Français du Cheval et de I'Equitation and INRAE for PhD salary support.

\section{Author contribution statement}

All authors contributed to the conceptualization of the review, $S \mathrm{~L}$ analysed the data, $S \mathrm{~L}$ and $\mathrm{A} d \mathrm{M}$ prepared the figures, tables and the first draft of the manuscript and all authors reviewed and edited the manuscript.

\section{Acknowledgements}

We would like to thank Elaine Shervill, Anne Kahler and Jessica Roach for assistance with collection and/or sectioning and staining of tissue sections.

\section{References}

Acker DA, Curran S, Bersu ET \& Ginther OJ 2001 Morphologic stages of the equine embryo proper on days 17 to 40 after ovulation. American Journal of Veterinary Research 62 1358-1364. (https://doi.org/10.2460/ ajvr.2001.62.1358)

Ahn DG, Ruvinsky I, Oates AC, Silver LM \& Ho RK 2000 tbx20, a new vertebrate T-box gene expressed in the cranial motor neurons and developing cardiovascular structures in zebrafish. Mechanisms of Development 95 253-258. (https://doi.org/10.1016/s09254773(00)00346-4)

Aleksic D, Blaschke L, Mißbach S, Hänske J, Weiß W, Handler J, Zimmermann W, Cabrera-Sharp V, Read JE, Mestre AM et al. 2016 Convergent evolution of pregnancy-specific glycoproteins in human and horse. Reproduction 152 171-184. (https://doi.org/10.1530/REP-16-0236)

Allen WR, Gower S \& Wilsher S 2007 Immunohistochemical localization of vascular endothelial growth factor (VEGF) and its two receptors (Flt-I and $\mathrm{KDR}$ ) in the endometrium and placenta of the mare during the oestrous cycle and pregnancy. Reproduction in Domestic Animals 42 516-526. (https://doi.org/10.1111/j.1439-0531.2006.00815.x)

Allen WRT, Gower S \& Wilsher S 2017 Localisation of epidermal growth factor (EGF), its specific receptor (EGF-R) and aromatase at the maternofetal interface during placentation in the pregnant mare. Placenta $\mathbf{5 0}$ 53-59. (https://doi.org/10.1016/j.placenta.2016.12.024)

Antczak DF \& Allen WR 1989 Maternal immunological recognition of pregnancy in equids. Journal of Reproduction and Fertility: Supplement 37 69-78.

Antczak DF, de Mestre AM, Wilsher S \& Allen WR 2013 The equine endometrial cup reaction: a fetomaternal signal of significance. Annual Review of Animal Biosciences 1 419-442. (https://doi.org/10.1146/ annurev-animal-031412-103703)

Arai KY, Tanaka Y, Taniyama H, Tsunoda N, Nambo Y, Nagamine N, Watanabe G \& Taya K 2006 Expression of inhibins, activins, insulinlike growth factor-I and steroidogenic enzymes in the equine placenta. Domestic Animal Endocrinology 31 19-34. (https://doi.org/10.1016/j. domaniend.2005.09.005)

Bacon SJ, Ellis SA \& Antczak DF 2002 Control of expression of major histocompatibility complex genes in horse trophoblast. Biology of Reproduction 66 1612-1620. (https://doi.org/10.1095/ biolreprod66.6.1612)

Betteridge KJ, Eaglesome MD, Mitchell D, Flood PF \& Beriault R 1982 Development of horse embryos up to twenty two days after ovulation: observations on fresh specimens. Journal of Anatomy 135 191-209. 
Brosnahan MM, Miller DC, Adams M \& Antczak DF 2012 IL-22 is expressed by the invasive trophoblast of the equine (Equus caballus) chorionic girdle. Journal of Immunology 188 4181-4187. (https://doi. org/10.4049/jimmunol.1103509)

Brosnahan MM, Silvela EJ, Crumb J, Miller DC, Erb HN \& Antczak DF 2016 Ectopic trophoblast allografts in the horse resist destruction by secondary immune responses. Biology of Reproduction 95 135. (https:// doi.org/10.1095/biolreprod.115.137851)

Budik S, Palm F, Walter I, Helmreich M \& Aurich C 2012 Increasing expression of oxytocin and vasopressin receptors in the equine conceptus between days 10 and 16 of pregnancy. Reproduction, Fertility, and Development 24 641-648. (https://doi.org/10.1071/RD11167)

Burns EN, Bordbari MH, Mienaltowski MJ, Affolter VK, Barro MV, Gianino F, Gianino G, Giulotto E, Kalbfleisch TS, Katzman SA et al. 2018 Generation of an equine biobank to be used for functional annotation of animal genomes project. Animal Genetics 49 564-570. (https://doi.org/10.1111/age.12717)

Cabrera-Sharp V, Read JE, Richardson S, Kowalski AA, Antczak DF, Cartwright JE, Mukherjee A \& de Mestre AM 2014 SMAD1/5 signaling in the early equine placenta regulates trophoblast differentiation and chorionic gonadotropin secretion. Endocrinology 155 3054-3064. (https://doi.org/10.1210/en.2013-2116)

Charlton F, Bobek G, Stait-Gardner T, Price WS, Mirabito Colafella KM, Xu B, Makris A, Rye KA \& Hennessy A 2017 The protective effect of apolipoprotein in models of trophoblast invasion and preeclampsia. American Journal of Physiology: Regulatory, Integrative and Comparative Physiology 312 R40-R48. (https://doi.org/10.1152/ajpregu.00331.2016)

Choi YH, Harding HD, Hartman DL, Obermiller AD, Kurosaka S, McLaughlin KJ \& Hinrichs K 2009 The uterine environment modulates trophectodermal POU5F1 levels in equine blastocysts. Reproduction 138 589-599. (https://doi.org/10.1530/REP-08-0394)

Conley AJ \& Ball BA 2019 Steroids in the establishment and maintenance of pregnancy and at parturition in the mare. Reproduction 158 R197-R208. (https://doi.org/10.1530/REP-19-0179)

Contois LW, Nugent DP, Caron JM, Cretu A, Tweedie E, Akalu A, Liebes L, Friesel R, Rosen C, Vary C et al. 2012 Insulin-like growth factor binding protein-4 differentially inhibits growth factor-induced angiogenesis. Journal of Biological Chemistry 287 1779-1789. (https://doi.org/10.1074/ jbc.M111.267732)

de Mestre AM, Miller D, Roberson MS, Liford J, Chizmar LC, McLaughlin KE \& Antczak DF 2009 Glial cells missing homologue 1 is induced in differentiating equine chorionic girdle trophoblast cells. Biology of Reproduction 80 227-234. (https://doi.org/10.1095/ biolreprod.108.070920)

de Mestre A, Noronha L, Wagner B \& Antczak DF 2010 Split immunological tolerance to trophoblast. International Journal of Developmental Biology 54 445-455. (https://doi.org/10.1387/ijdb.082795ad)

de Mestre AM, Hanlon D, Adams AP, Runcan E, Leadbeater JC, Erb HN, Costa CC, Miller D, Allen WR \& Antczak DF 2011 Functions of ectopically transplanted invasive horse trophoblast. Reproduction 141 849-856. (https://doi.org/10.1530/REP-10-0462)

de Ruijter-Villani M, van Boxtel PRM \& Stout TAE 2013 Fibroblast growth factor-2 expression in the preimplantation equine conceptus and endometrium of pregnant and cyclic mares. Theriogenology $\mathbf{8 0}$ 979-989. (https://doi.org/10.1016/j.theriogenology.2013.07.024)

Dini P, Daels P, Loux SC, Esteller-Vico A, Carossino M, Scoggin KE \& Ball BA 2018 Kinetics of the chromosome 14 microRNA cluster ortholog and its potential role during placental development in the pregnant mare. BMC Genomics 19 954. (https://doi.org/10.1186/s12864-0185341-2)

Dini P, El-Sheikh Ali H, Carossino M, C. Loux S, Esteller-Vico A, E. Scoggin K, Daels P \& Ball BA 2019 Expression profile of the chromosome 14 microRNA cluster (C14MC) ortholog in equine maternal circulation throughout pregnancy and its potential implications. International Journal of Molecular Sciences 20 6285. (https://doi.org/10.3390/ijms20246285)

Dini P, Kalbfleisch T, Uribe-Salazar JM, Carossino M, Ali HE, Loux SC, Esteller-Vico A, Norris JK, Anand L, Scoggin KE et al. 2021 Parental bias in expression and interaction of genes in the equine placenta. PNAS 118 e2006474118. (https://doi.org/10.1073/pnas.2006474118)

Enders AC, Schlafke S, Lantz KC \& Liu IKM 1993 Endoderm cells of the equine yolk sac from day 7 until formation of the definitive yolk sac placenta. Equine Veterinary Journal 25 3-9. (https://doi. org/10.1111/j.2042-3306.1993.tb04814.x)

Ezashi T \& Imakawa K 2017 Transcriptional control of IFNT expression. Reproduction 154 F21-F31. (https://doi.org/10.1530/REP-17-0330)

Flaminio MJBF \& Antczak DF 2005 Inhibition of lymphocyte proliferation and activation: a mechanism used by equine invasive trophoblast to escape the maternal immune response. Placenta 26 148-159. (https:// doi.org/10.1016/j.placenta.2004.05.008)

Fushan AA, Turanov AA, Lee SG, Kim EB, Lobanov AV, Yim SH, Buffenstein R, Lee SR, Chang KT, Rhee H et al. 2015 Gene expression defines natural changes in mammalian lifespan. Aging Cell 14 352-365. (https://doi.org/10.1111/acel.12283)

Galera PD, Ribeiro CR, Sapp HL, Coleman J, Fontes W \& Brooks DE 2015 Proteomic analysis of equine amniotic membrane: characterization of proteins. Veterinary Ophthalmology 18 198-209. (https://doi. org/10.1111/vop.12190)

Gerstenberg C, Allen WR \& Stewart F 1999 Cell proliferation patterns during development of the equine placenta. Journal of Reproduction and Fertility 117 143-152. (https://doi.org/10.1530/jrf.0.1170143)

Gibson C, de Ruijter-Villani M \& Stout TAE 2017 Negative uterine asynchrony retards early equine conceptus development and upregulation of placental imprinted genes. Placenta 57 175-182. (https://doi.org/10.1016/j.placenta.2017.07.007)

Gibson C, de Ruijter-Villani M, Rietveld J \& Stout TAE 2018 Expression of glucose transporters in the endometrium and early conceptus membranes of the horse. Placenta 68 23-32. (https://doi.org/10.1016/j. placenta.2018.06.308)

Grant DM, Macedo A, Toms D \& Klein C 2020 Fibrinogen in equine pregnancy as a mediator of cell adhesion, an epigenetic and functional investigation. Biology of Reproduction 102 170-184. (https://doi. org/10.1093/biolre/ioz157)

Grünig G \& Antczak DF 1995 Horse trophoblasts produce tumor necrosis factor $\alpha$ but not interleukin 2, interleukin 4, or interferon $\gamma$. Biology of Reproduction 52 531-539. (https://doi.org/10.1095/biolreprod52.3.531)

Horii M, Li Y, Wakeland AK, Pizzo DP, Nelson KK, Sabatini K, Laurent LC, Liu Y \& Parast MM 2016 Human pluripotent stem cells as a model of trophoblast differentiation in both normal development and disease. PNAS 113 E3882-E3891. (https://doi.org/10.1073/pnas.1604747113)

Hughes M, Dobric N, Scott IC, Su L, Starovic M, St-Pierre B, Egan SE, Kingdom JCP \& Cross JC 2004 The Hand1, Stra13 and Gcm1 transcription factors override FGF signaling to promote terminal differentiation of trophoblast stem cells. Developmental Biology 271 26-37. (https://doi. org/10.1016/j.ydbio.2004.03.029)

Iqbal K, Chitwood JL, Meyers-Brown GA, Roser JF \& Ross PJ 2014 RNA-Seq transcriptome profiling of equine inner cell mass and trophectoderm. Biology of Reproduction 90 61. (https://doi.org/10.1095/ biolreprod.113.113928)

Janečka JE, Davis BW, Ghosh S, Paria N, Das PJ, Orlando L, Schubert M, Nielsen MK, Stout TAE, Brashear W et al. 2018 Horse Y chromosome assembly displays unique evolutionary features and putative stallion fertility genes. Nature Communications 9 2945. (https://doi.org/10.1038/ s41467-018-05290-6)

Jaworska J, Ropka-Molik K, Piórkowska K, Szmatoła T, Kowalczyk-Zięba I, Wocławek-Potocka I \& Siemieniuch M 2021. Transcriptome Profiling of the Retained Fetal Membranes-An Insight in the Possible Pathogenesis of the Disease. Animals 11 675. (https://doi.org/10.3390/ani11030675)

Jolma A, Yin Y, Nitta KR, Dave K, Popov A, Taipale M, Enge M, Kivioja T, Morgunova E \& Taipale J 2015 DNA-dependent formation of transcription factor pairs alters their binding specificity. Nature 527 384-388. (https:// doi.org/10.1038/nature15518)

Kalbfleisch TS, Rice ES, DePriest MS, Walenz BP, Hestand MS, Vermeesch JR, O'Connell BL, Fiddes IT, Vershinina AO, Saremi NF et al. 2018 Improved reference genome for the domestic horse increases assembly contiguity and composition. Communications Biology 1197. (https://doi.org/10.1038/s42003-018-0199-z)

Klein C \& Troedsson MHT 2011 Transcriptional profiling of equine conceptuses reveals new aspects of embryo-maternal communication in the horse. Biology of Reproduction 84 872-885. (https://doi.org/10.1095/ biolreprod.110.088732)

Klein C, Scoggin KE, Ealy AD \& Troedsson MHT 2010 Transcriptional profiling of equine endometrium during the time of maternal recognition 
of pregnancy. Biology of Reproduction 83 102-113. (https://doi. org/10.1095/biolreprod.109.081612)

Klohonatz KM, Cameron AD, Hergenreder JR, da Silveira JC, Belk AD, Veeramachaneni DN, Bouma GJ \& Bruemmer JE 2016 Circulating miRNAs as potential alternative cell signaling associated with maternal recognition of pregnancy in the mare. Biology of Reproduction 95124. (https://doi.org/10.1095/biolreprod.116.142935)

Kolakowska J, Souchelnytskyi S, Saini RKR \& Franczak A 2017 Proteomic analysis of the endometrium during early pregnancy in the domestic pig. Reproduction, Fertility, and Development 29 2255-2268. (https://doi. org/10.1071/RD16435)

Lange-Consiglio A, Lazzari B, Perrini C, Pizzi F, Stella A, Cremonesi F \& Capra E 2018 MicroRNAs of equine amniotic mesenchymal cell-derived microvesicles and their involvement in anti-inflammatory processes. Cell Transplantation 27 45-54. (https://doi.org/10.1177/0963689717724796)

Lassaline ME, Brooks DE, Ollivier FJ, Komaromy AM, Kallberg ME \& Gelatt KN 2005 Equine amniotic membrane transplantation for corneal ulceration and keratomalacia in three horses. Veterinary Ophthalmology 8 311-317. (https://doi.org/10.1111/j.1463-5224.2005.00405.x)

Legacki EL, Scholtz EL, Ball BA, Stanley SD, Berger T \& Conley AJ 2016 The dynamic steroid landscape of equine pregnancy mapped by mass spectrometry. Reproduction 151 421-430. (https://doi.org/10.1530/REP15-0547)

Legacki EL, Ball BA, Corbin CJ, Loux SC, Scoggin KE, Stanley SD \& Conley AJ 2017 Equine fetal adrenal, gonadal and placental steroidogenesis. Reproduction 154 445-454. (https://doi.org/10.1530/ REP-17-0239)

Legacki EL, Scholtz EL, Ball BA, Esteller-Vico A, Stanley SD \& Conley AJ 2019 Concentrations of sulphated estrone, estradiol and dehydroepiandrosterone measured by mass spectrometry in pregnant mares. Equine Veterinary Journal 51 802-808. (https://doi.org/10.1111/ evj.13109)

Lennard SN, Stewart F \& Allen WR 1995 Insulin-like growth factor II gene expression in the fetus and placenta of the horse during the first half of gestation. Journal of Reproduction and Fertility 103 169-179. (https:// doi.org/10.1530/jrf.0.1030169)

Loux SC, Scoggin KE, Bruemmer JE, Canisso IF, Troedsson MH, Squires EL \& Ball BA 2017 Evaluation of circulating miRNAs during late pregnancy in the mare. PLoS ONE 12 e0175045. (https://doi.org/10.1371/journal. pone.0175045)

Loux SC, Dini P, El-Sheikh Ali H, Kalbfleisch T \& Ball BA 2019a Characterization of the placental transcriptome through mid to late gestation in the mare. PLoS ONE 14 e0224497. (https://doi.org/10.1371/ journal.pone.0224497)

Loux SC, Fernandes CB, Dini P, Wang K, Wu X, Baxter D, Scoggin KE, Troedsson MHT, Squires EL \& Ball BA 2019b Small RNA (sRNA) expression in the chorioallantois, endometrium and serum of mares following experimental induction of placentitis. Reproduction, Fertility, and Development 31 1144-1156. (https://doi.org/10.1071/RD18400)

Loux SC, Conley AJ, Scoggin KE, El-Sheikh Ali H, Dini P \& Ball BA 2020 New insights in equine steroidogenesis: an in-depth look at steroid signaling in the placenta. Reproduction 160 65-82. (https://doi. org/10.1530/REP-20-0015)

Mansour TA, Scott EY, Finno CJ, Bellone RR, Mienaltowski MJ, Penedo MC, Ross PJ, Valberg SJ, Murray JD \& Brown CT 2017 Tissue resolved, gene structure refined equine transcriptome. BMC Genomics 18 103. (https:// doi.org/10.1186/s12864-016-3451-2)

Masui S, Ohtsuka S, Yagi R, Takahashi K, Ko MSH \& Niwa H 2008 Rex1/Zfp42 is dispensible for pluripotency in mouse ES cells. BMC Developmental Biology 8 45. (https://doi.org/10.1186/1471213X-8-45)

Noronha LE \& Antczak DF 2012 Modulation of T-cell reactivity during equine pregnancy is antigen independent. American Journal of Reproductive Immunology 68 107-115. (https://doi.org/10.1111/j.16000897.2012.01154.x)

Noronha LE, Huggler KE, de Mestre AM, Miller DC \& Antczak DF 2012 Molecular evidence for natural killer-like cells in equine endometrial cups. Placenta 33 379-386. (https://doi.org/10.1016/j. placenta.2012.01.018)

Oddsdóttir C, Riley SC, Leask R, Shaw DJ, Aurich C, Palm F, Fowden AL, Ricketts SW \& Watson ED 2011 Dynamics of activities of matrix metalloproteinases-9 and -2 , and the tissue inhibitors of MMPs in fetal fluid compartments during gestation and at parturition in the mare. Theriogenology 75 1130-1138. (https://doi.org/10.1016/j. theriogenology.2010.11.023)

Oriol JG, Betteridge KJ, Hardy J \& Sharom FJ 1993 Structural and developmental relationship between capsular glycoproteins of the horse (Equus caballus) and the donkey (Equus asinus). Equine Veterinary Journal 25 14-18. (https://doi.org/10.1111/j.2042-3306.1993.tb04816.x)

Parsons Aubone AM, Bisiau CM, McCue PM \& Bouma GJ 2020 Presence of clock genes in equine full-term placenta. Journal of Animal Science $\mathbf{9 8}$ skaa094. (https://doi.org/10.1093/jas/skaa094)

Posfai E, Rovic I \& Jurisicova A 2019 The mammalian embryo's first agenda: making trophectoderm. International Journal of Developmental Biology 63 157-170. (https://doi.org/10.1387/ijdb.180404ep)

Raeside JI, Christie HL, Waelchli RO \& Betteridge KJ 2009 Estrogen metabolism by the equine embryo proper during the fourth week of pregnancy. Reproduction 138 953-960. (https://doi.org/10.1530/REP09-0235)

Raeside JI, Christie HL, Waelchli RO \& Betteridge KJ 2012 Biosynthesis of oestrogen by the early equine embryo proper. Reproduction, Fertility, and Development 24 1071-1078. (https://doi.org/10.1071/RD11275)

Rambags BPB, van Tol HTA, van den Eng MM, Colenbrander B \& Stout TAE 2008 Expression of progesterone and oestrogen receptors by early intrauterine equine conceptuses. Theriogenology 69 366-375. (https:// doi.org/10.1016/j.theriogenology.2007.10.011)

Rapacz-Leonard A, Leonard M, Chmielewska-Krzesinska M, PazdziorCzapula K \& Janowski T 2018 Major histocompatibility complex class I in the horse (Equus caballus) placenta during pregnancy and parturition. Placenta 74 36-46. (https://doi.org/10.1016/j.placenta.2018.12.006)

Read JE, Cabrera-Sharp V, Offord V, Mirczuk SM, Allen SP, Fowkes RC \& de Mestre AM 2018a Dynamic changes in gene expression and signalling during trophoblast development in the horse. Reproduction 156 313-330. (https://doi.org/10.1530/REP-18-0270)

Read JE, Cabrera-Sharp V, Kitscha P, Cartwright JE, King PJ, Fowkes RC \& de Mestre AM 2018b Glial cells missing 1 regulates equine chorionic gonadotrophin beta subunit via binding to the proximal promoter. Frontiers in Endocrinology 9 195. (https://doi.org/10.3389/ fendo.2018.00195)

Reinholt BM, Bradley JS, Jacobs RD, Ealy AD \& Johnson SE 2017 Tissue organization alters gene expression in equine induced trophectoderm cells. General and Comparative Endocrinology 247 174-182. (https:// doi.org/10.1016/j.ygcen.2017.01.030)

Riley P, Anson-Cartwright L \& Cross JC 1998. The Hand1 bHLH transcription factor is essential for placentation and cardiac morphogenesis. Nature Genetics 18 271-275. (https://doi.org/10.1038/ng0398-271)

Robles M, Peugnet P, Dubois C, Piumi F, Jouneau L, Bouchez O, Aubrière MC, Dahirel M, Aioun J, Wimel L et al. 2018 Placental function and structure at term is altered in broodmares fed with cereals from mid-gestation. Placenta 64 44-52. (https://doi.org/10.1016/j. placenta.2018.02.003)

Robles M, Loux S, de Mestre A M \& Chavatte-Palmer P 2022 Environmental constraints and pathologies that modulate equine placental genes and development. Reproduction 163 R25-R38. (https://doi.org/10.1530/REP21-0116)

Saben J, Zhong Y, McKelvey S, Dajani NK, Andres A, Badger TM, GomezAcevedo H \& Shankar K 2014 A comprehensive analysis of the human placenta transcriptome. Placenta 35 125-131. (https://doi.org/10.1016/j. placenta.2013.11.007)

Scaravaggi I, Borel N, Romer R, Imboden I, Ulbrich SE, Zeng S, Bollwein H \& Bauersachs S 2019 Cell type-specific endometrial transcriptome changes during initial recognition of pregnancy in the mare. Reproduction, Fertility, and Development 31 496-508. (https:// doi.org/10.1071/RD18144)

Seo MS, Park SB, Kim HS, Kang JG, Chae JS \& Kang KS 2013 Isolation and characterization of equine amniotic membrane-derived mesenchymal stem cells. Journal of Veterinary Science 14 151-159. (https://doi. org/10.4142/jvs.2013.14.2.151)

Sferruzzi-Perri AN, Sandovici I, Constancia M \& Fowden AL 2017 Placental phenotype and the insulin-like growth factors: resource allocation to fetal growth. Journal of Physiology 595 5057-5093. (https:// doi.org/10.1113/JP273330)

Smits K, Govaere J, Peelman LJ, Goossens K, de Graaf DC, Vercauteren D, Vandaele L, Hoogewijs M, Wydooghe E, Stout T et al. 2012 Influence of 
the uterine environment on the development of in vitro-produced equine embryos. Reproduction 143 173-181. (https://doi.org/10.1530/REP-110217)

Soncin F, Khater M, To C, Pizzo D, Farah O, Wakeland A, Rajan KAN, Nelson KK, Chang CW, Moretto-Zita M et al. 2018 Comparative analysis of mouse and human placentae across gestation reveals species-specific regulators of placental development. Development 145. (https://doi. org/10.1242/dev.156273)

Stout TAE \& Allen WR 2002 Prostaglandin E(2) and F( 2 alpha) production by equine conceptuses and concentrations in conceptus fluids and uterine flushings recovered from early pregnant and dioestrous mares. Reproduction 123 261-268. (https://doi.org/10.1530/rep.0.1230261)

Wade CM, Giulotto E, Sigurdsson S, Zoli M, Gnerre S, Imsland F, Lear TL, Adelson DL, Bailey E, Bellone RR et al. 2009 Genome sequence, comparative analysis, and population genetics of the domestic horse. Science 326 865-867. (https://doi.org/10.1126/science.1178158)

Walters KW, Corbin CJ, Anderson GB, Roser JF \& Conley AJ 2000 Tissue-specific localization of cytochrome P450 aromatase in the equine embryo by in situ hybridization and immunocytochemistry. Biology of Reproduction 62 1141-1145. (https://doi.org/10.1095/ biolreprod62.5.1141)

Wang X, Miller DC, Clark AG \& Antczak DF 2012 Random X inactivation in the mule and horse placenta. Genome Research 22 1855-1863. (https://doi.org/10.1101/gr.138487.112)

Wang X, Miller DC, Harman R, Antczak DF \& Clark AG 2013 Paternally expressed genes predominate in the placenta. PNAS 110 10705-10710. (https://doi.org/10.1073/pnas.1308998110)
Yan Y, Peng H, Wang P, Wang H \& Dong M 2016 Increased expression of fatty acid binding protein 4 in preeclamptic placenta and its relevance to preeclampsia. Placenta 39 94-100. (https://doi.org/10.1016/j. placenta.2016.01.014)

Yang QE, Giassetti MI \& Ealy AD 2011 Fibroblast growth factors activate mitogen-activated protein kinase pathways to promote migration in ovine trophoblast cells. Reproduction 141 707-714. (https://doi.org/10.1530/ REP-10-0541)

Zavy MT, Vernon MW, Sharp DC \& Bazer FW 1984 Endocrine aspects of early pregnancy in pony mares: a comparison of uterine luminal and peripheral plasma levels of steroids during the estrous cycle and early pregnancy. Endocrinology 115 214-219. (https://doi.org/10.1210/endo115-1-214)

Zhang YC, Qin XL, Ma XL, Mo HQ, Qin S, Zhang CX, Wei XW, Liu XQ, Zhang Y, Tian FJ et al. 2021 CLDN1 regulates trophoblast apoptosis and proliferation in preeclampsia. Reproduction 161 623-632. (https://doi. org/10.1530/REP-20-0677)

Received 16 March 2021

First decision 27 April 2021

Revised manuscript received 6 January 2022

Accepted 13 January 2022 